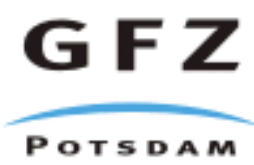

Originally published as:

de Wit, M., Horsfield, B. (2007): Built on the shoulders of Alfred Wegener and Alex du Toit to apply German precision technology to the geological superlatives of South Africa. - South African Journal of Geology, 110, 2-3, 165-174

DOI: 10.2113/gssajg.110.2-3.165. 


\title{
Built on the shoulders of Alfred Wegener and Alex du Toit to apply German precision technology to the geological superlatives of South Africa
}

\author{
Maarten de Wit \\ GFZ - GeoForschungsZentrum Potsdam,Telegraphenberg, 14473 Potsdam, Germany, \\ and AEON - Africa Earth Observatory Network, University of Cape Town, Rondebosch, 7700, South Africa
} e-mail: maarten.dewit@uct.ac.za

\author{
Brian Horsfield \\ GeoForschungsZentrum Potsdam, Telegrafenberg, 14473 Potsdam, Germany \\ email: horsf@gfz-potsdam.de
}

(c) 2007 September Geological Society of South Africa

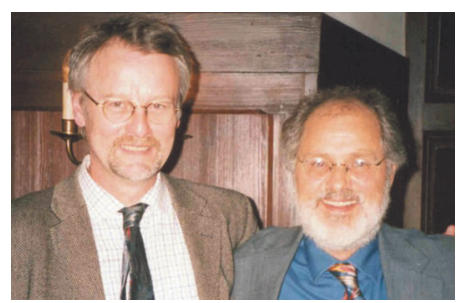

Brian Horsfield and Maarten de Wit

\section{Introduction}

Welcome to this Special Issue of the South African Journal of Geology comprising the first results from Inkaba yeAfrica, a truly major scientific undertaking of the German and South African earth science communities. Since 2004, teams of scientists from both countries have been surveying a cone-shaped sector of the Earth from its core to space, enclosing South Africa and the Southern Oceans at its solid surface, and tracking the history and interactions of its components into the past. South Africa was chosen as the research site since it is, in our humble and unbiased opinion, quite simply the best natural laboratory in the world. Its geology retains the longest best-preserved record of tectonic movements, volcanic events, natural resource emplacement, geomagnetic record, and climatic change extending back more than 3000 million years. Southern Africa is also the current focus of dramatic changes in the Earth's magnetic field and is the cradle of human culture. Our "simple" goal has been to understand fundamental processes. This volume attests to the significant steps that have already been taken in advancing our knowledge of the solid earth, its component fluids, and the interfaces to the hydrosphere, atmosphere and biosphere.

Our work, and thence the papers in this volume, is divided into three interlinked categories, namely Heart of Africa, Living Africa and Margins of Africa. Heart of Africa concerns energy transfer from core to space. The development and deployment of land-based monitoring technologies, and networking with data from satellite monitoring systems feature strongly. The growth of the South Atlantic magnetic hole and its effects are under scrutiny. The feedback mechanisms between hot upwelling mantle beneath southern Africa and its present surface elevation are under examination. Living Africa is a geophysical, geological and geochemical investigation of the oceans, sediments, resources and climate that developed between and around the margins of southern Africa, South America and Antarctica since Gondwana break-up. Margins of Africa focuses on the causes and mechanisms of continental break-up, and investigates the nature of ocean-continent boundary, the crust and the Beattie Anomaly, using seismic reflection and refraction surveys, and magnetotelluric measurements.

Young scientists from both countries have contributed to this volume as part of work performed during their Masters, Ph.D or Postdoctoral positions, running under the auspices of Inkaba yeAfrica's Capacity Building Initiative. This is living proof that the programme continues to provide both the initial impetus and a continuing stable vehicle for training young South Africans in holistic Earth system science. The outlook is a foundation for modern university teaching and research that is in tune with the economic and social needs of their developing nation.

\section{Background and forecast}

The origin of Inkaba yeAfrica goes back to 2001 when discussions about how to better link the Earth science communities in South Africa and Germany were initiated by Professor Rolf Emmermann (then Chief Executive Officer of GeoForschungsZentrum-Potsdam, Germany), Dr. Khotso Mokhele and Dr. Gerhard von Gruenewaldt (then President and Vice-President of the National Research Foundation, respectively) during the instalment phases of the super-conducting gravimeter at the Sutherland Astronomical Observatory in the Western Cape. This led to a draft proposal and an exploratory workshop - Geodynamic South Africa - its continental margins and its evolving environment - held at the 


\section{An Holistic Evaluation of Planet Earth}

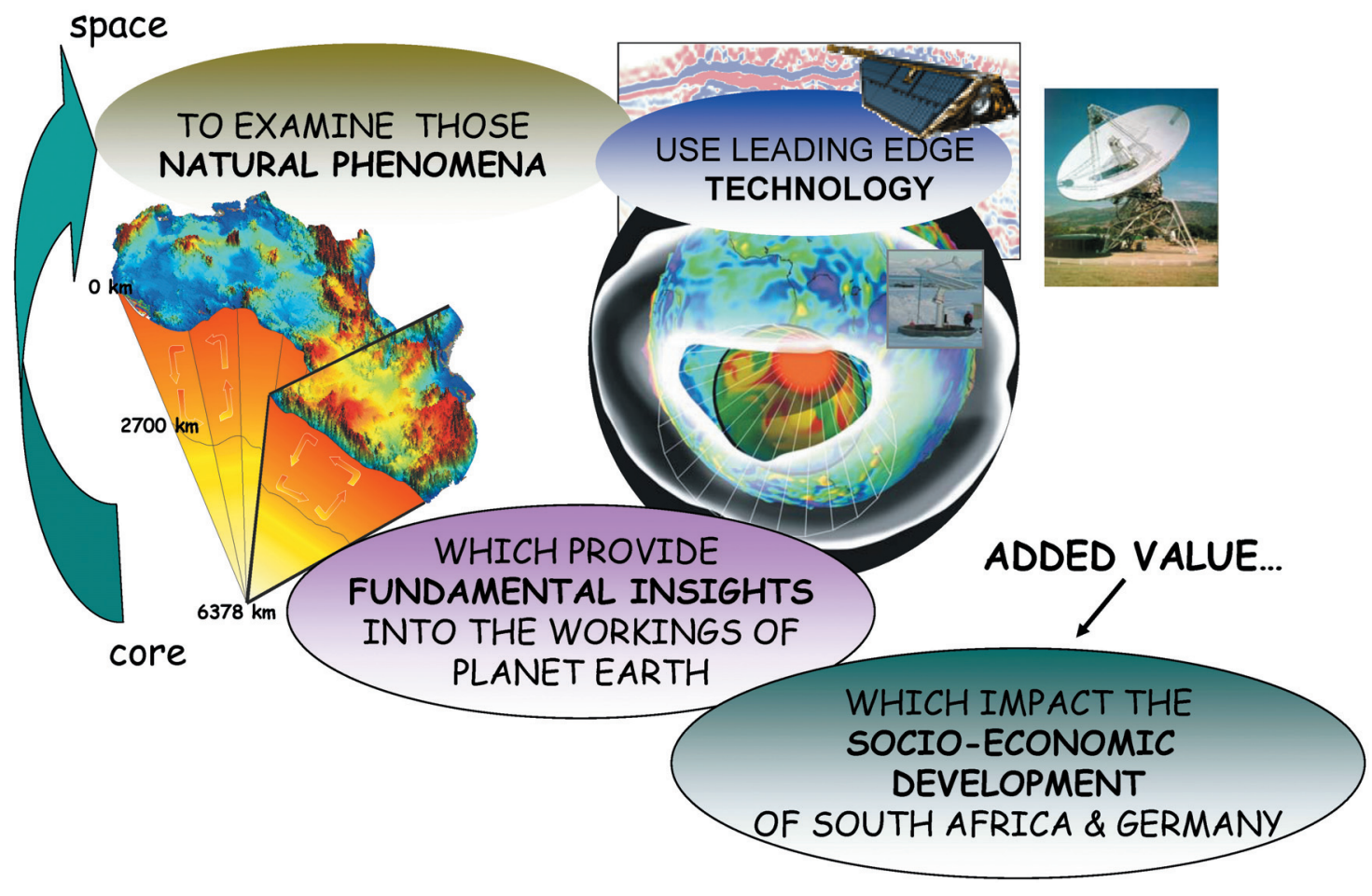

Figure 1. Inkaba ye Africa - Earth System studies in a cone-shaped sector of the Earth from the core to space.

University of Cape Town, in November 2002. The workshop was attended by 106 scientists from South African universities, the Council for Geoscience, the Petroleum Agency SA, CSIR and a number of South African mining and energy companies, as well as 25 scientists from Germany, representing GFZ-Potsdam, Alfred-Wegener-Institute (AWI), and BGR-Hannover. Looking back, this actually yielded what was a very heterogeneous programme, admittedly full of potential, but with very little cohesion. Nevertheless, it was already clear that the spark was there. Striking while the iron was hot, Professor Emmermann stepped forward and committed to the funding of a second workshop in Potsdam, a mere four months later. A first draft for a collaborative Earth Systems Science project was prepared during this second workshop, and a final proposal shortly thereafter. It was Professor S. Sayto of the Dept of African Languages at UCT, who suggested the name Inkaba yeAfrica: Inkaba is a Xhosa word encapsulating a sense of total interconnectivity. Literally it means navel, the central point, a point from which all energy, material and knowledge emerges and is recycled. Uniting this with yeAfrica creates the broader meaning Earth Systems (Science) of Africa.

Inkaba yeAfrica was born at that spring workshop of 2003, the heterogeneous mix of proposals being molded into an aggressive and state-of-the-art research initiative for selling science and capacity building together.
In South Africa, the final proposal was presented to the NRF in October 2003 and to DST in early 2004. Professor Kevin Burke (University of Houston, Texas; MIT, Cambridge; and the Carnegie Institution, Washington, USA) supported the proposal in the journal "Science" in April 2004 (Volume 304, 380-381). The first Inkaba yeAfrica project got underway in March 2004, with a deep electrical sounding experiment in the Karoo near Beaufort West. Initial results of this first experiment were presented at the annual meeting of AGU (American Geophysical Union) in San Francisco, 11 to 17 December 2004. Since then, annual workshops have alternated between South Africa (2005, Cape Town -94 participants; 2007 Durban) and Germany (2006, Potsdam -58 participants), and a review paper about Inkaba yeAfrica and its progress was published in the Transactions of the American Geophysical Union, EOS, in March 2006. Many German and South African students interacted whilst they participated actively in field experiments in South Africa and during ocean cruises. A large number of postgraduate students have participated in the Inkaba yeAfrica workshops, EGU and AGU conferences, reporting on their Inkaba yeAfrica work through talks and posters. In addition, nine South African students and a postdoctoral fellow have been chosen for extended research visits at the GFZ for more specialized training, and are now completing their advanced degrees. 


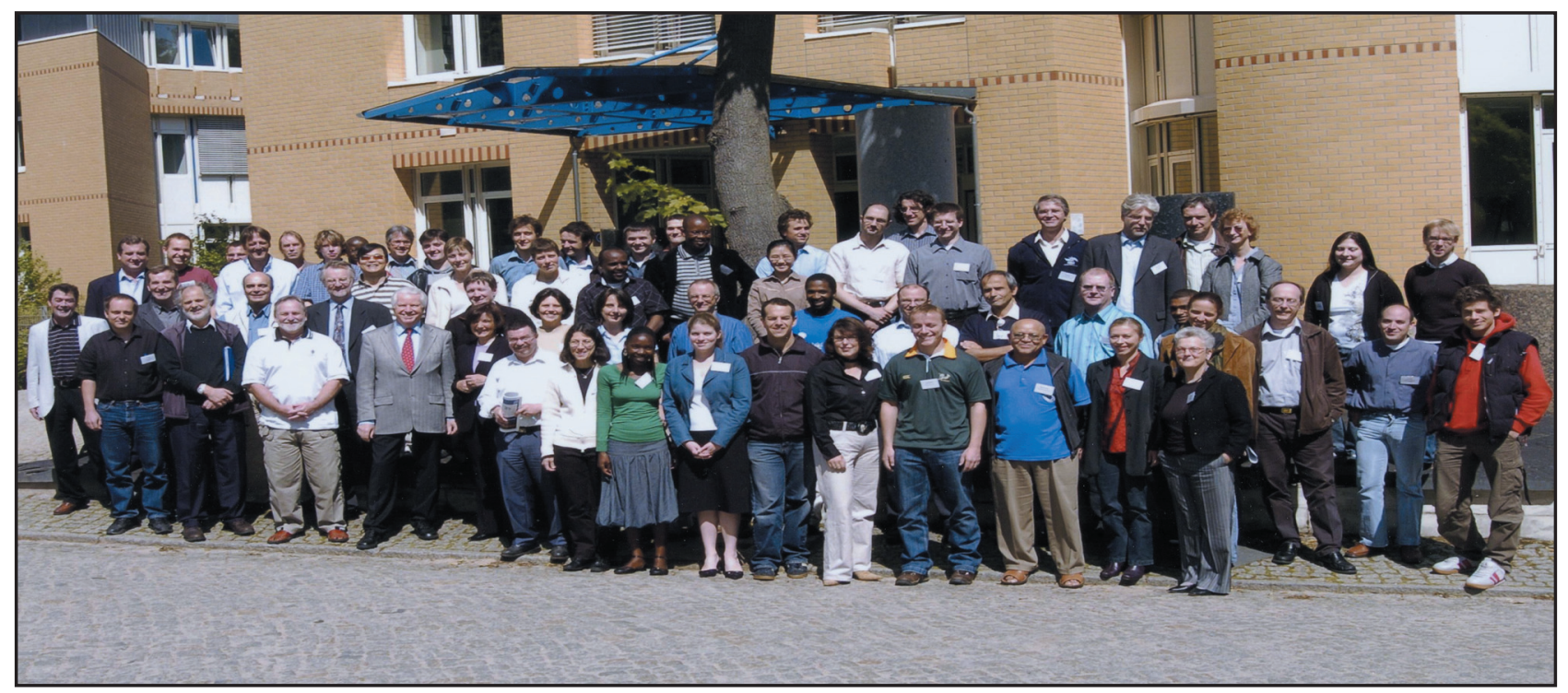

Figure 2. Fourth Inkaba yeAfrica workshop group at the GeoForschungsZentrum, Potsdam, Germany

Having waxed eloquently about its humble beginnings and path to fame, it is remarkable that Inkaba yeAfrica has never had its own funding per se. In both Germany and South Africa, third party funding has had to be sought, and we have worked tirelessly to get German and South African funding agencies on board. In South Africa, Khotshe Mokhele and Gerhard von Gruenewald always were champions of our cause, and it is clear that their and Rolf Emmermann's efforts in Germany were crucial in getting the component parts of Inkaba yeAfrica funded. In South Africa these efforts have resulted in the funding of postdoctoral researchers and Ph.Ds, and the training of M.Sc and Honours level students, and the purchase of computer facilities, microscopes and GPS-stations. Offshore and onshore geophysical surveys have been a central theme of the Margins of Africa studies, and it is thanks to AWI and BGR (offshore) and GFZ (onshore) that these extremely expensive surveys actually came about.

While we have proudly seen Inkaba yeAfrica held aloft as a flagship project in South Africa, it is also clear that this flagship has travelled through some calm and very stormy seas. We thank Robert Kriger and Val Munsami on the South African side for throwing lifelines in times of trouble, and it is with a view to adding a stabilizing element that we have recently founded www.inkaba.org and a central office in Gauteng to act as a vehicle for scientific, cultural, political, and educational information exchange.

The publication of this volume coincides with the 5th scientific Inkaba yeAfrica workshop in Durban (October 22 to 23, 2007), where the results of the first phase of four years research, experimentation and training will be reviewed. At the same time new avenues, new partners, new ideas will be explored towards beginning Phase II of Inkaba yeAfrica, creating a bigger umbrella of national and international cooperation. Already, the theme 'Margins of Africa' is dovetailing with a newly funded German Priority
Programme: South Atlantic Margin Processes and Links with onshore Evalution (SAMPLE). Similarly, 'Living Africa' will hopefully expand its perspectives and blossom under new GFZ leadership, endeavouring to incorporate more remote sensing for environmental and ecodynamic studies, with possible new 'nerve' centers at the universities of the Free State and Fort Hare. 'Heart of Africa' plans enlargement through the possible building of a new Earth and Space Observatory at Matjiesfontein in the Karoo, which will facilitate closer integration of satellite-based Inkaba yeAfrica research with the Hermanus Magnetic Observatory. The deploying of monitoring devices is a crucial strategy of Inkaba yeAfrica. The tragic Indian Ocean tsunami has hammered home the necessity to accelerate and expand the scope of risk reduction, and has placed earth science high on the political agenda both in Germany and South Africa. This way forward should ensure a greater and broader platform from which to expand the capacity building goal of Inkaba yeAfrica, to emergence of young geoscience leaders born in and from the new South Africa.

\section{This volume - first science successes and new questions}

There are twenty four papers in this special volume, more or less equally divided between the three themes. The first 8 contributions represent work in the 'Heart of Africa' theme, of which the first three papers deal with present observations of the magnetic field of southern Africa, and how to link these observations with historical measurements with which to make predictions about its future behaviour; and, crucially, how to improve the robustness and number of measurements and observations. Geomagnetic field variations monitored by local South African observatories and German satellites, including the high-resolution satellite CHAMP, reveal a major South Atlantic anomaly where the geomagnetic field is significantly weaker than over the rest of the 
Earth at equivalent altitudes. This local weak geomagnetic field severely reduces its shielding effect of lethal cosmic energy waves, with potentially grave consequences for interference in communication systems of satellites and high-flying aircraft. To be able to forecast further increases and fluctuations of this 'magnetic hole' is of considerable interest to the global community.

The present-day geomagnetic field currently displays a dramatic decrease of global strength that might be associated with the early stages of a geomagnetic reversal, i.e. a complete change of field polarity. The southern African region features exceptionally strong geomagnetic secular variation and a region of reverse magnetic flux at the core-mantle boundary. Mandea and her colleagues review the state of our understanding of these dynamic changes and present examples of recent improvements in our knowledge of the core magnetic field and its secular variation over this specific region, and look into future evolution of the magnetic field in this arena. Understanding these changes relies on being able to make accurate measurements and reliable forecasts. All three papers of this section underscore the need to improve facilities for continuous observations to facilitate uninterrupted data flows. In this respect, the South African Hermanus Magnetic Observatory (HMO) has been a 'beacon' of the southern hemisphere as it has documented a decrease in the magnetic field strength of about 26 percent since the 1920s. Over the last five years, new geomagnetic ground measurement and satellite monitoring equipment has been tested, put in place, or is presently under deployment, to gather higher resolution data that may help unravel the workings of the dynamo processes in the Earth's core and at its core-mantle boundary. Proof of successful collaboration between GFZ and the HMO is the increase from 8 to 40 repeat stations throughout South Africa, Namibia and Botswana. Korte and coworkers report on this and on optimising the southern Africa repeat station surveys using a portable variometer, whilst Kotzé et al. present the first regional geomagnetic field models based on this new magnetic field data. In late 2005, new measurement campaigns were initiated to compile a detailed map of secular variations. In addition, a new geomagnetic observatory for permanent monitoring of the field will be established later this year at Gamsberg in Namibia. Results of these new developments will be forthcoming in the near future.

The next four papers deal with space related observations that have particular relevance for understanding earth systems behaviour, including the influence of sun-cycles and atmospheric vapour content on climate variations, crustal deformation studies and earth-tide models. As with the magnetic field measurement, the majority of these studies rely on being able to make continuous observations from space with accurately located and well-surveyed sites on the ground. The solid Earth reacts to internal and external forces by undergoing rotational accelerations, mass displacements, and continuous deformation that in turn affects the position of a space geodetic system located on the surface of the Earth. One of the aims of Inkaba yeAfrica, therefore, has been to install a number of new reliable Global Positioning System - GPS - stations in and around southern Africa, and the islands of the southern oceans and Antarctica, to accurately monitor these ongoing surface distortions from space. In 2006/2007, five new such stations were purchased and have been or are in process of being deployed at Lilongwe (Malawi), Harare (Zimbabwe), Sani (Lesotho), Kosi Bay (South Africa) and Marion Island. In this volume, Combrinck and co-workers describe the rationale to enlarge this network within the SADC countries, and to build a new southern African Space Geodesy and Earth Observatory to continuously monitor this network locally. A ground and geotechnical survey of a proposed site for such a new observatory was completed in 2006. The site is in the southern Karoo, near Matjiesfontein. The proposed observatory is envisaged to function as a new geodetic site as part of a global network, and appears suitable to house a permanent differential global navigation satellite system, a lunar laser ranger and radio telescope antennas for Very Long Baseline Interferometry (VLBI) studies to determine Earth rotations and tectonic plate motions. Recent recognition that east Africa comprises a number of subplates whose shapes, motions and seismic activities are still relatively ill-defined justifies establishing this new observatory. And other important observations could also be made there. Moeketsi et al. describe the importance of such an observatory and ground-based GPS network to monitor space weather effects on the ionosphere over southern Africa. They describe how this is used to show that the total values of electron content in the ionosphere above over South Africa is directly related to cycles of solar flares. This knowledge is central for future application in high frequency radio communication, navigation, positioning, frequency management, and for understanding earth system behavior and impacts of fluctuations in solar radiation on climate change over southern Africa. Combrinck and Suberlak present their preliminary results of new satellite laser-ranging techniques that model satellite orbits to great accuracy and test different earth-tide models and other transient and permanent surface deformations of the solid earth. In doing so, they quantify the distortion effect that non-inclusion of station displacements due to earth-tides has on computating satellite orbits. In addition, Combrink et al define a time-series of precipitable water vapour (PWV) derived from continuous GPS observations at two South African GPS stations. Since water vapour is a major greenhouse gas, observed changes in atmospheric PWV could be indicative of weather and climate change. Their main contribution is a realistic noise model of the PWV observations that provides robust conclusions about the 

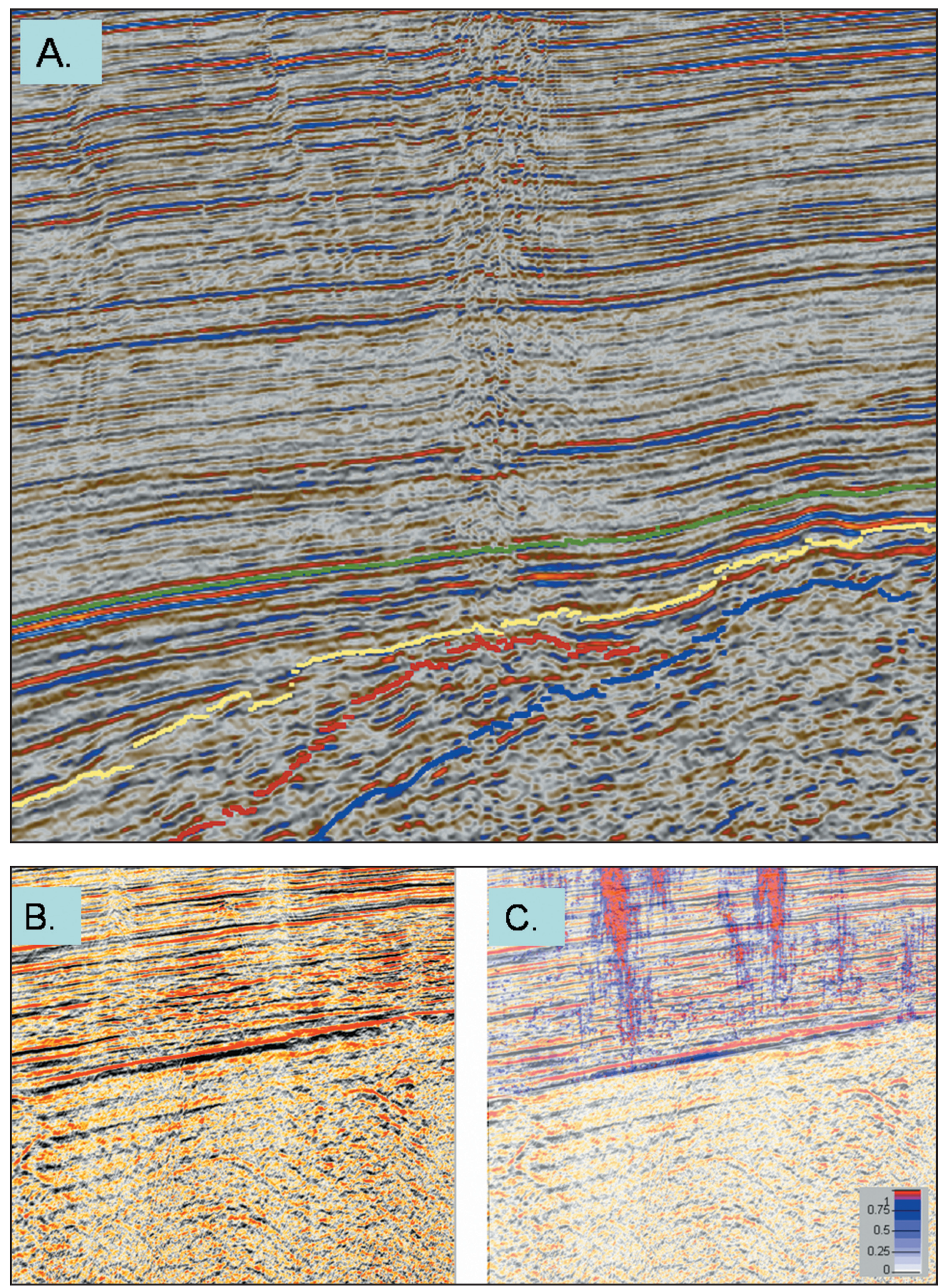

Figure 3. (A) Gas seeps at stratigraphic pinch-outs, Orange Basin: (B) seismic attributes used to train a neural network: (C) the trained neural network recognises subtle seepage phenomena in the same profile. 
significance of the derived PWV increase or decrease for given time spans, as long as this is measured over a period longer than five years. They find no statistically significant PWV trends at the two GPS stations between 1998 and 2006.

The side-effects of interaction between extraterrestrial energy such as cosmic rays with solid matter at the surface of the Earth, allow geologists to determine the rates of rock erosion and formation of landscapes. The last paper of this section describes the measurements of cosmogenic nuclides produced in rocks during their exposure to cosmic rays. The surface exposure time of rocks can be calculated from the concentration of such cosmogenic nuclides in the rock and, in turn, this enables us to deduct rock erosion rates.

Kounov et al., describe their cosmogenic dating studies across the top and along the edge of the high (Kalahari) plateau in South Africa. Their analyses of the in situ produced cosmogenic ${ }^{3} \mathrm{He}$ and ${ }^{21} \mathrm{Ne}$ concentrations yield values of vertical erosion rates for quartzite between 1 to $2 \mathrm{~m} / \mathrm{Ma}$ and for dolerite between 2 to $3 \mathrm{~m} / \mathrm{Ma}$. In addition, their careful sampling strategy allows them to demonstrate that variations in local climate and lithology both control the resulting erosion patterns across large regions of South Africa.

The next nine contributions report on the work in the 'Living Africa' theme, starting with deep structure, moving up through the sedimentary sequences and finally looks at surface and near-surface features. The west coast is marked by an anomalously strong deep-sourced gravity high that is analyses in the paper by Hirsch et al. using 3D crustal models. They test a geological model with a homogenous middle and lower crust to derive the position of the Moho for an isostatically balanced system. The best-fit model to the seismic and gravity data predicts extensive mafic material in the middle and lower crust, and an abrupt change to less dense material to reproduce the adjacent gravity low. The case for such mafic underplating dovetails well with similar conclusions from a $\sim 800 \mathrm{~km}$ long amphibian (off-shore-onshore) wide-angle seismic refraction line to the north that was completed at an early stage of the Inkaba yeAfrica program, but which is not yet published (Neben et al., in progress). South Africa, like all industrialised nations will continue to be dependant on fossil fuels for some time to come. Security of supply and optimum utilisation of national resources are key issues. An understanding of hydrocarbon generation, migration and seepage in the Orange Basin is being achieved through petroleum system modelling. Paton et al. describe their 3-D seismic stratigraphic approach, integrated with sedimentological data and thermal modelling of this passive margin, and present a new geological model. At the end of the Mesozoic, the Cretaceous Atlantic margin is controlled by the interplay of subsidence and pre-existing bathymetry, with some eustatic modulation, while the Cenozoic development is controlled by both a significant Paleogene/Neogene change in the location of accommodation space and margin instability. The change in location of deposition through time has a strong influence on sediment loading and hence maturation of the principal Mid-Cretaceous hydrocarbon source rocks. This research explores feedback loops toward predicting and testing the generation and migration of hydrocarbons and their expulsion into the ocean-atmosphere system. The presence of gas chimneys reveals the petroleum system leaks, and signals a natural escape of greenhouse gases into the atmosphere. To what degree this causes global warming is still under investigation.

Related projects are starting to resolve details of the major reorganization of the paleo-ocean currents of the southern oceans around South Africa -the South African gateway - over the last 50 million years or so, and in particular, following the opening of the Drake Passage at $\sim 41 \mathrm{Ma}$ and its significant deepening subsequently at $\sim 34 \mathrm{Ma}$. The South African gateway, comprising the region from the Cape Basin in the west via the Agulhas Passage in the south across the Agulhas Plateau to the Transkei Basin and Natal Valley in the east, represents a critical bottleneck within the global oceanic circulation circuit. Here, the warm Agulhas Current (AC), cold Antarctic Bottomwater (AABW), North Atlantic Deep Water (NADW), Antarctic Intermediate Water (AAIW), and Benguela Current (BC) water masses from the Atlantic and Indian-Pacific Oceans meet, mix, and exchange heat. This heat transfer helps to maintain the global deep-ocean conveyor belt. Locally, these different water masses also have a strong impact on the regional climate. In the next paper, Uenzelmann-Neben and co-workers present new seismic reflection data that suggest an active bottom current in the southern Cape Basin, the Agulhas Passage and across the Agulhas Plateau operated as early as Early Eocene-Early Oligocene (50 to $30 \mathrm{Ma}$ ). The path of this bottom current characterises it as a proto-AABW. In the Early Oligocene to Middle Miocene (30 to $12 \mathrm{Ma}$ ), a current equivalent to AAIW/Agulhas Retroflection leaves its oldest traces on the eastern Agulhas Plateau, and evidence for the existence of the Benguela Current in Early Miocene $(\sim 24 \mathrm{Ma})$ can be found in the Cape Basin. Then, with the onset of NADW in the Mid Miocene to Early Pliocene (12 to $3 \mathrm{Ma}$ ), the branch of AABW flowing through the Agulhas Passage is weakened and finally deflected to the south in the Early Pliocene-Holocene times ( 3 to $0 \mathrm{Ma}$ ). AAIW/Agulhas Retroflection appears strongest on the eastern Agulhas Plateau in Early Pliocene-Holocene probably as a result of the onset of northern hemisphere glaciation. Whilst observed variations in strength the Benguela Current are likely related to climate variations linked to glacialinterglacial cycles.

The effect of changing oceanic environmental conditions are also expressed in the fine details of chemical stratigraphy along the Atlantic coast and in the geochemistry of ferromanganese nodules dredged from the Mozambique Ridge and Basin farther to the east. 


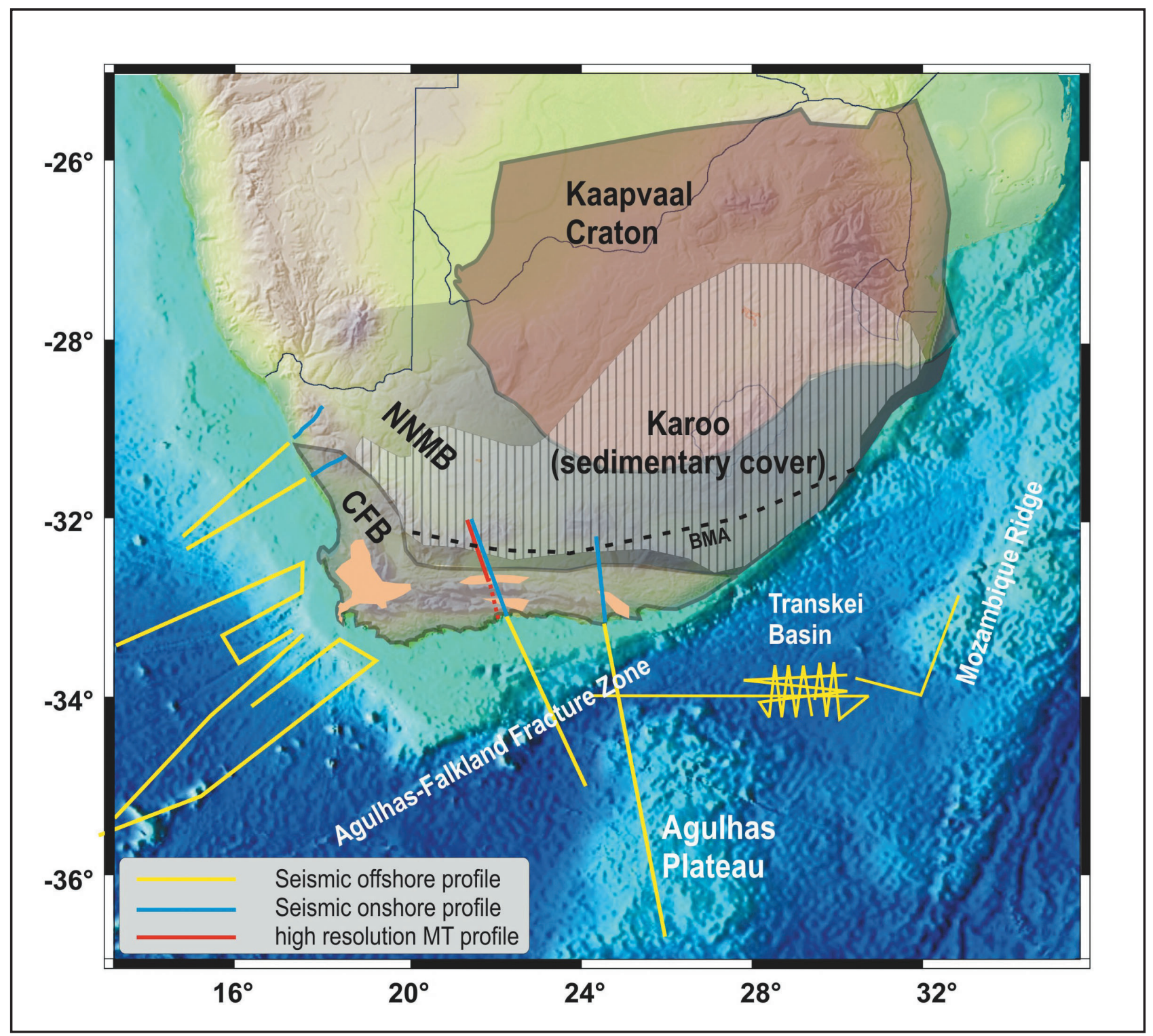

Figure 4. Locations of two onshore/offshore seismic refection/refraction and MCS lines across the west coast of South Africa and two lines across the southern margin of South Africa. The Agulhas Karoo Geoscience Transect in the south is complemented with offshore seismic reflection investigation in the Transkei Basin. Magnetotelluric data were collected along two profiles on land. NNMB: Namaqua Natal Mobile Belt, CFB: Cape Fold Belt, BMA: Beattie Magnetic Anomaly.

Perrit and Watkeys define three different mineralisation zones in this area: deep-water basin deposits, ridge-flank deposits formed below the base of the oxygen minimum layer, and ridge-crest deposits formed within the oxygen minimum layer. Mineralisation is predominantly controlled by hydrogenetic mineralisation processes, but the presence of a hydrothermal geochemical signature and abundant volcanic glass shards embedded within the ferromanganese matrix suggests that there has been recent magmatic activity and volcanism on the Mozambique Ridge.

The western continental margin of South Africa is a site of intense upwelling and high productivity. It acts as a repository for large quantities of terrigenous sediment delivered by wind and rivers, most notably those from the Orange River. Within the last two million years, the continental shelf of the west coast evolved into a major sink for terrigenous mud and organic matter, supporting feedback links of the carbon sub cycles that track glacial to interglacial fluctuations. Accurate dating is important to link the global climate change and the complex dynamics along this margin. In the first of two following papers, Herbert and Compton present 32 new radiocarbon ages of mollusk shells and foraminifera tests recovered from an 11 myr long record of Holocene organic-rich mud deposits on the middle-inner shelf (the mudbelt), and from calcareous ooze on the continental slope. Low sediment accumulation rates of $\sim 0,25$ $\mathrm{mm} /$ year are recorded in the Holocene mudbelt, whereas slope cores have sedimentation rates $<0,22$ $\mathrm{mm}$ /year. Shifts in the mudbelt depo-centre has occurred over the last $2 \mathrm{Kyr}$ in response to changes in sea level and accommodation space on the shelf. 
They also show that onshore Orange River paleoflood deposits provide a terrestrial record of the last $12 \mathrm{kyr}$, and thus provide unique potential to linking highresolution continental and marine records. In turn, these records will allow direct comparison of Holocene oceanographic and terrestrial climatic changes in and around southern Africa. Further progress in this work is needed to track the details of climate change in the southern hemisphere at a higher resolution. Next, Compton and Maake use proxies such as suspended loads in the Orange River to describe decadal and centennial records of recent times on this shelf linked to terrestrial records of megaflood events, and to past precipitation patterns across southern Africa. Farther inland such detailed climate-proxy studies are ongoing on cored lake deposits of the Tswang Crater near Pretoria. Kristen et al. report on this work in the next paper, and on their quest to resolve the organic chemistry of biomarkers and link these to the biodiversity changes of the surrounding vegetation and in turn to climate variations. This work is still in need of more robust and precise dating to improve regional modeling. Such dating might come from work on stalagmites in inland and coastal caves that is still in progress.

Collectively, these projects will provide a highresolution history of coupled ocean-atmospherebiosphere changes in this part of the world. In future, coupled high-resolution astro- and magneto-stratigraphy might shed further light on the kinematics of these changes, and their possible additional links to space-, mantle-, and core-processes. This will however require a much better understanding of the first order links between topographic evolution, sediment accumulation and plume activity below southern Africa. A move towards this might be to better quantify chemical effects of surface processes and surface runoff. To this effect, De Villiers and de Wit report on their chemical study of rivers draining the Archean granite-gneissic terrains of Swaziland and present the first anomalous $\mathrm{Sr}-{ }^{87} \mathrm{Sr} /{ }^{86} \mathrm{Sr}$ data for a river system outside the Himalayas. They show that the implicit assumption in river chemical weathering studies that high carbonate weathering is required to explain high dissolved load Sr-concentrations is incorrect. These findings require some serious rethinking about the rates of silicate weathering based on such chemical proxies.

Topographically, south and central Africa is dominated by the high Kalahari Plateau surrounded by passive continental boundaries and far away from any compressive plate boundary. Globally this is tectonically unique. Inland the margin of the plateau is marked by a prominent escarpment whose origin remains obscure. Reconstructing the evolution of southern Africa's landscapes and in particular the origin of the high plateau remains an enigmatic phenomenon. In the last paper of this section, de Wit summarizes the main features and multiple working-hypothesis for the origin, timing and extent of the plateau uplift, and discusses the suspected feedback between the Kalahari epeirogeny, mantle upwelling, topography, weathering and climate. The age of the main Kalahari uplift is now well documented to be Cretaceous, but the uplift history is not simple. Apatite fission-track studies implicate at least two punctuated episodes of rapid uplift and exhumation in the Mid- and Late-Cretaceous. These two events coincide with two frequency maxima of mantle-derived kimberlite intrusions in South Africa. Thus, for the first time, a direct link across much of southern Africa may be established between increased uplift, regional erosion rates and punctuated episodes of positive mantle buoyancy. Seismic stratigraphy shows that these distinct episodes are also clearly recorded in the sediment accumulation rates in basins off the west- and south- coast. This remarkable convergence of results will need further testing, particularly using 3-D seismic data and incorporating more onshore dating of erosion surfaces. This is ongoing work. Another important aspect of the uplift involves the concomitant erosion of the Karoo basalts in the Late Cretaceous, and the extensive effect this must have had on $\mathrm{CO}_{2}$ content of the atmosphere at the time, and in turn on the long term climate change to a cooler Cenozoic world.

The last seven contributions in the volume summarize some of the ongoing work in the theme 'Margins of Africa'. A first order quest of this theme has been to better define the transition from the continents to oceans, both at surface and deep into the lithosphere. Restoring these continental boundaries and tracking their evolution helps to test and model the causes and consequences of the breakout of southern Africa from its Gondwana configuration. Central to this research is a series of onshore-offshore geophysical transects across the three different continental margin types of South Africa.

Since 2004, several amphibious experiments have been completed across the western and southern margins. A final amphibious traverse is planned for 2007 across the east (Indian Ocean) continental margin of Mozambique. The first two papers describe the preliminary results of two $800 \mathrm{~km}$ long amphibian seismic refraction lines across the ocean-continent boundary of the south coast of South Africa carried out in April 2005. This is the first time a deep seismic profile has been attempted in this region. The geophysical transect across the southern margin stretches from the oceanic Agulhas Plateau across the Agulhas-Falkland Fracture Zone (AFFZ) at the continent-ocean boundary. Onland the transect cuts across the Cape Fold belt, the Karoo basin, and the world's largest terrestrial magnetic anomaly, the Beattie Anomaly (BA) associated with a large electrical conductive belt (the Southern Cape Conductive Belt). The origin of these two deep geophysical features is not understood. New information about these comes from an $\sim 100 \mathrm{~km}$ deep crust seismic reflection line parallel to the central portion of the onland refraction profile and two adjacent $\sim 100 \mathrm{~km}$ long high-resolution magnetotelluric (MT) lines. 
Parsiegla and co-workers present the first relatively detailed image of the velocity-depth structure of the margin from the Agulhas Passage to the Agulhas Bank along the western offshore profile. The continental shelf is about $250 \mathrm{~km}$ wide and the crust thins from $\sim 40 \mathrm{~km}$ at the coast to $\sim 20 \mathrm{~km}$ near the continent-ocean transition zone flanking the AFFZ that is relatively narrow ( $\sim 52 \mathrm{~km}$, as is typical for sheared margins) and where the depth to Moho rises steeply to $\sim 7 \mathrm{~km}$. The upper crust beneath the southern Outeniqua Basin and the Diaz Marginal Ridge is likely made up of deformed Paleozoic Cape-Karoo metasediments that overlie a crystaline basement, and are covered by Cretaceous and younger deposits. Thus, it is possible that vestiges of the Cape Fold Belt might occur right up to the ocean continent boundary, whilst its underlying crystalline basement appears to connect with that farther inland where the seismic reflection data links it to crust of Namaqua age (Mesoproterozoic). This is consistent with ages of dredged continental rocks found in places along the deeper offshore ridges, as well as that identified as basement in the Falkland Islands. Almost no stratified sediment cover exists on the oceanic crust in the Agulhas Passage, outboard of the AFFZ, because of strong erosion due to ocean currents. However, volcanic flows within in the AFFZ region may represent magmatic activity in this zone. Next, Stankiewicz and co-workers, describe the onshore part this seismic line, and a second one $\sim 200 \mathrm{~km}$ to the west, from the South African coast across the Cape Fold Belt, Beattie Magnetic Anomaly, the Karoo Basin, up to the Great Escarpment. The presented data and interpretations are restricted to the upper crust down to depths of $\sim 30 \mathrm{~km}$. Whilst work to extend this to Moho depths is ongoing, these onshore sections delineate particularly well the geometry of the Cretaceous normal listric faults to minimum depths of $15 \mathrm{~km}$ that formed during the marked crustal thinning offshore. They also observe a high velocity anomaly within the Namaqua basement at $\sim 10 \mathrm{~km}$ depth that these workers relate to the source of the Beattie Magnetic Anomaly. The latter is better imaged by complex reflectors along a detailed seismic reflection profile across the Karoo basin. This line is reported on in the next two papers. First, Lindeque et al. describe in detail the results from their $\sim 100 \mathrm{~km}$ near-vertical reflection seismic profile across the Karoo Basin up to the escarpment that was generated using controlled source shots at $\sim 500 \mathrm{~m}$ spacing. The data is of excellent quality and delineates for the first time a well-defined Moho at $\sim 40 \mathrm{~km}$ below the southern Karoo basin increasing to $\sim 45 \mathrm{~km}$ below the front of the Cape Fold Belt, as well as a clear subdivision of the crust into at least three distinct layers. The upper layer displays with great clarrity the subhorizontal layering of the Cape Supergroup below a more folded Karoo sequence, and local décollement structures close to carbonaceous shales of the Whitehill Formation. A well-defined midcrustal layer is likely the subsurface continuation of the granitoid gneisses of Bushmanland sub-province of the Namaqua-Natal Orogenic Belt. This layer hosts the Beattie Magnetic Anomaly (BMA) at 7 to $15 \mathrm{~km}$ depth, in a $\sim 10 \mathrm{~km}$ wide zone of complex reflectors. Surprisingly, the internal seismic fabric of this crustal layer dips to the north. The underlying lower crustal layer may represent granulite-gneisses of the Namaqua sub-province. The internal seismic fabric in the upper part of this layer dips both to the north and south, but a north dipping fabric dominates the lower part. A possible $\sim 1$ to $2 \mathrm{~km}$ thick lowermost crustal layer of high seismic reflectivity, overlies the Moho and may represent underplated mafic material. Next, Bräuer et al., derive shallow tomographic P- and S- velocity models for the upper 1 to $1.5 \mathrm{~km}$ along this section line. Their seismic signatures can be matched with confidence to fold structures geologically mapped at surface.

The next two papers summarize results from high resolution magnetotelluric (MT) experiments carried out along the same line as the detailed seismic section, and two other profiles close by. These lines were specifically designed to image the Beattie Anomaly. A surprising byproduct of this was the delineation of a highly conductive layer in the Karoo basin that has the potentially to be accurately mapped out regionally in subsurface. In the first paper, Weckmann and co-workers describe the results of this MT experiment. These are the first high resolution MT depth sounding profiles across the Beattie Anomaly, and they reveal a zone of high electrical conductivity at a depth of $\sim 5$ to 10 kilometers. The MT profiles have now been extended across the Kaapvaal craton boundary and in particular the black carbon- and pyrite-rich Whitehill Formation of the middle Karoo Supergroup is perfectly imaged. Existing borehole data here shows this layer to be about 50-70 m thick. In the next paper, Branch et al. report their detailed analyses on borehole samples of the Whitehill Formation and provide a set of petrographic data and conductivity measurements that are consistent with the in situ conductivity response of the Whitehill Formation to the MT probing. Having determined this stratigraphic link, the MT data can now be used to delineate the Whitehill Formation across the entire length of the section and used to better define the shape of the structural features of this basin, which is of great interest for new basin modeling.

The Atlantic margin of southern Africa is a classic example of a volcanic rifted margin, and exhibits a pronounced north-south gradient in both volume and temperature of the mantle-derived magmatism that accompanied continental break-up at about $130 \mathrm{Ma}$. In the last paper of this volume, Trumbull and co-workers have examined the geochemistry of Early Cretaceous dolerite dike swarms that occur along the coast from the Etendeka province of Namibia in the north, to the Cape Peninsula in the south. Variation in $\mathrm{MgO}$ compositions of the dolerite dikes provide insights into the conditions and causes of mantle melting along segments with high and low magma flux. 
The northern segment is characterised by large volumes of flood basalts, numerous intrusive ring complexes and dyke swarms. However, $2000 \mathrm{~km}$ to the south, in the Cape Province, igneous activity appears to have been relatively low and restricted to diffuse dyke swarms. Deep seismic experiments, which will be reported on elsewhere, confirm this distinct north-south variation in magmatic intensity in one respect, but challenges it in another. On the one hand, the thickness of underplated basalt of the lower crust decreases from about $20 \mathrm{~km}$ off-shore northern Namibia, to $<7 \mathrm{~km}$ off the coast of the western Cape. On the other hand, the seaward-dipping reflector sequences that are believed to represent the volcanic equivalents of the underplated magmas reveal no major differences in volume along the same length of the margin. Quantifying and understanding these differences in breakup-related magmatism along the rifted margin will provide answers to the controversial questions on the role of mantle plumes in continental rifting.

Collectively, we believe the results of the Inkaba yeAfrica programme as reported in this volume are of interest to a wide spectrum of academic and industrial workers. There will of course be more to come, but this 'smorgasbord' is a good start towards achieving the integrated story that Inkaba yeAfrica set out to achieve. In particular, we are pleased that some of the work carried out by the Inkaba yeAfrica students, shown in the accompanying photograph (page 164), has been included in this volume, and this reflects positively about capacity building through the dedication of multi-mentor teams, particularly at GFZ-Potsdam, that encouraged them to publish despite the short time frame. We acknowledge the hard work of Marian Tredoux at the start of Inkaba yeAfrica which initiated the involvement of students.

Finally, as editors of this volume, we would like to thank all the referees (see list opposite) and authors for helping to create what we all hope will be a volume of lasting value to earth system science in South African studies. Special thanks to Jay Barton and Lew Ashwal for their editorial guidance and hard work, and Claudia Röhl and Nazla Hassen for invaluable assistance in chasing authors, referees, manuscripts and deadlines. We also sincerely thank all our German and South African colleagues, students, farmers and administrators that have invested so generously in this project. Finally, we would like to thank our financial sponsors. In South Africa this came through the DST, NRF, the Council for Geoscience and UCT; in Germany through GFZ-Potsdam, Alfred-Wegener-Institute, and the Bundesanstalt für Geowissenschaften und Rohstoffe.

We trust that you will enjoy reading this volume as much as we enjoyed putting it together.

August, 2007.

\section{Referee acknowledgement}

We express our grateful thanks to the following referees for their efficient and professional services:

Miryam Bar-Matthews (Geological Survey of Israel, Israel)

David Bell (Arizona State University, United States of America)

Martin Bromann Klausen (University of Kwazulu-Natal, South Africa)

Ron Clowes (University of British Columbia, Canada)

John Compton (University of Cape Town, South Africa)

David Cronan (Imperial College London, United Kingdom)

Stephanie de Villiers (University of Stellenbosch, South Africa)

Reginald Domoney (University of Western Cape, South Africa)

Moctar Doucouré (De Beers Geophysics, Southdale, South Africa)

Gunnar Elgered (Onsala Space Observatory, Sweden)

Kerry Gallagher (Université de Rennes, France)

Gerald Garland (United Arab Emirates University, United Arab Emirates)

Bruce Goleby (Geoscience Australia, Perth, Australia)

Ludwig Grunwald (GeoForschungsZentrum Potsam, Germany)

Arne Hoffmann-Rothe (Bundesanstalt für Geowissenschaften und

Rohstoffe, Germany)

Hielke Jelsma (De Beers Exploration, Southdale, South Africa)

Dougal Jerram (University of Durham, United Kingdom)

Alan Jones (Dublin Institute for Advanced Studies, Ireland)

Jürgen Kusche (GeoForschungsZentrum Potsam, Germany)

Richard Langley (University of New Brunswick, Canada)

Mike Meadows (University of Cape Town, South Africa)

Eoin Moran (Valentia Observatory, Ireland)

Mark Muller (Dublin Institute for Advanced Studies, Ireland)

Jochen Naeth (BP Exploration \& Operating Co. Limited, United Kingdom) Gesa Netzeband (IFM-Geomar, Kiel, Germany)

Isabelle Panet (Institut Géographique National, Marne-la-Vallée, France),

John Rogers (University of Cape Town, South Africa

Reinhard Sachsenhofer (Montan-Universität Leoben, Austria)

Joerg Schaefer (Lamont-Doherty Earth Observatory, New York, United

States of America)

Howie Scher (University of Rochester, United States of America)

Harald Schuh (Technische Universität Wien, Austria)

Gerhard Schwarz (Geological Survey, Uppsala, Sweden)

Angelo de Santis (Istituto Nazionale di Geofisica e Vulcanologia, Italy)

Philippe Sorrel (Université de Caen Basse Normandie, France)

Alan Thomson (British Geological Survey, United Kingdom)

Miguel Torta (Ebre Observatory, Roquetes, Spain)

Gulio Viola (Geological Survey of Norway, Trondheim, Norway)

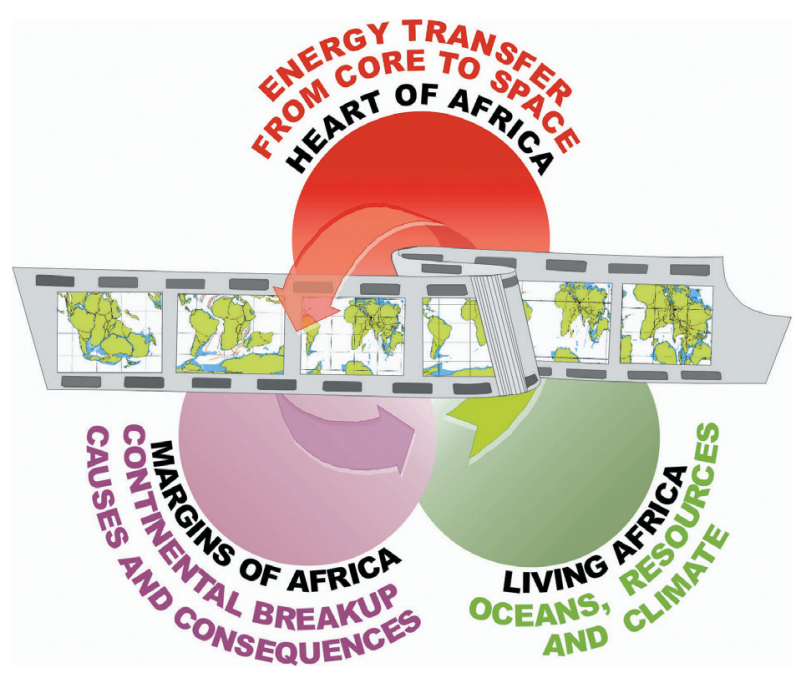

